\title{
Metabolic Studies in a Patient with Idiopathic Hypercalciuria
}

\author{
C. E. DENT,* M.D. ; LYAL WATSON,* M.B.
}

Brit. med. F., 1965, 2, 449-452

In 1939 Flocks focused attention on the fact that the urinary excretion of calcium is high in many patients who form calcium-containing renal stones. This was again emphasized by Hodgkinson and Pyrah (1958), who found a high daily urinary excretion of calcium much more frequently in their stone-forming patients than in their controls. The difference was particularly marked in males.

Albright et al. (1953) introduced the term "idiopathic hypercalciuria" to describe a syndrome of renal stone formation with high urinary calcium excretion, normal plasma calcium, and frequently a low plasma phosphorus level. They suggested that renal tubular damage, possibly due to staphylococcal pyelonephritis, was the primary lesion. The syndrome was much more common in male patients. The same group (Henneman et al.) reported further experience in 1958, by which time it was clear that most of these hypercalciuric patients belonged to this idiopathic group. Considerable interest has since arisen in trying to explain the mechanism of the hypercalciuria. Henneman et al. found a low faecal calcium in four of their patients and concluded, "if the finding of a decreased faecal calcium excretion is confirmed in further patients it would strengthen the suspicion that this hypercalciuria reflects a metabolic cause and not merely a peripheral renal defect." Parfitt et al. (1964) have reported a low faecal calcium in five patients with idiopathic hypercalciuria.

Several authors have discussed the relative importance of a renal tubular leak or an excessive gastro-intestinal absorption of calcium as the primary defect. Jackson and Dancaster (1959) thought that a renal leak was primary, and postulated that, " as a general bodily principle, when there is excessive loss of calcium in the urine the intestine will compensate as far as possible by an increased absorption of calcium." Hodgkinson (1961) pointed out that the syndrome was not necessarily homogeneous and that the important factor might be a renal tubular leak in some cases and gastro-intestinal overabsorption in others.

The exact mechanisms of renal stone formation are still poorly understood even in hypercalciuric subjects. Indeed it appears to us that hypercalciuria has not been adequately defined, and this is the subject of a further investigation in this department, where we have found a number of healthy controls with high 24-hour urinary calcium levels. Hodgkinson and Pyrah (1958) also found a number of symptomless individuals in their normal population with a high urinary calcium excretion, and Jackson and Dancaster (1959), who obtained similar results, referred to these as "healthy hypercalciurics." Furthermore, Fleisch (1962) has shown that most urines are supersaturated with calcium phosphate and calcium oxalate, while Fleisch and Bisaz (1962a, 1962b) and others have demonstrated the presence in urine of inhibitory substances which may prevent the precipitation of minerals and offer an explanation of the high supersaturation even of normal urine with calcium salts.

Nevertheless, whatever other factors may also be concerned it would still seem to be worth while to reduce the urinary calcium excretion in patients with renal stones and a high * Member of the Medical Unit, University College Hospital Medical
School, London. urinary calcium output. Several measures, such as a lowcalcium diet and additional oral phytate, have been tried to this end, and Dent et al. (1964) have reported experience with the use of oral cellulose phosphate, a compound which can inhibit dietary calcium absorption. The present paper describes our investigations and treatment by dietary calcium restriction over a period of six years of a patient suffering from idiopathic hypercalciuria and renal stone formation. $\mathrm{He}$ presented special problems of dietary control due to a remarkable sensitivity to dietary calcium intake. We are unaware of such long-term follow-up studies on other similar patients.

\section{Case Report}

An Australian dentist, born in November 1925, had good health until 1948, when he developed an attack of right-sided renal colic. $X$-ray pictures taken at that time showed a stone in the right ureter and several stones in the left kidney. The stone in the right ureter was removed at the Royal Prince Alfred Hospital, Sydney, in 1948. About six months later he developed for the first time colicky pain on the left side. He was advised to drink a lot of water, and has continued to do so ever since.

During the next eight years he had several attacks of left-sided renal colic and passed three stones per urethram. In 1956, after another attack of left-sided renal colic, he was investigated at the Royal Prince Alfred Hospital, Sydney, where he was found to have a high urinary calcium excretion (about $600 \mathrm{mg}$. daily). He was then given salicylamide tablets. In 1957 he came to live in England.

In May 1958 he took a course of cod-liver-oil capsules, one daily for two weeks. He then had a further attack of renal colic and was first seen in the Metabolic Ward at U.C.H. in June of that year. He was a well-looking man aged 32 . There was no family history of renal stone formation. His parents were well and were not related. His brother and two sisters were also in good health. There were no physical abnormalities. His weight was $78.5 \mathrm{~kg}$. (173 lb.), height $176 \mathrm{~cm}$. (5 ft. 9 in.) and blood-pressure 145/90. There was no corneal calcification.

\section{Preliminary Investigations}

Plasma calcium $9.9 \mathrm{mg} . / 100 \mathrm{ml}$. Plasma phosphorus $2.7 \mathrm{mg} . /$ $100 \mathrm{ml}$. 24-hour urinary calcium $605 \mathrm{mg}$. in a volume of $3,640 \mathrm{ml}$. Plasma urea $30 \mathrm{mg} . / 100 \mathrm{ml}$., sodium $146 \mathrm{mEq} / \mathrm{l}$., potassium $4.2 \mathrm{mEq} / 1$., chloride $104 \mathrm{mEq} / 1$., bicarbonate $23.4 \mathrm{mEq} / 1$. Blood $p H$ 7.45. $X$-ray pictures of chest and lumbar spine were normal. I.V.P. showed multiple stones in the calices of the left kidney, with a larger stone in the stem of the upper group of calices. Above this the calices were dilated, with thinning of the overlying cortex. There were no stones in the right kidney or either ureter. He was advised to take a low-calcium diet containing about $500 \mathrm{mg}$. of calcium a day.

On 28 August 1958 he was admitted to the Metabolic Ward of U.C.H. for investigation. His history and physical findings were unchanged, and further investigations performed were as follows: plasma calcium $10.0 \mathrm{mg} . / 100 \mathrm{ml}$., plasma phosphorus $3.7 \mathrm{mg} . /$ $100 \mathrm{ml}$., plasma alkaline phosphatase 6 K.A. units $/ 100 \mathrm{ml}$., plasma albumin 4.5 g. $/ 100 \mathrm{ml}$, globulin 2.1 g. $/ 100 \mathrm{ml}$. Serum electrophoretic strip showed no abnormality. Urinary examination showed 0.1 part of protein $/ 1,000,2-4$ pus cells and occasional red cells per $\frac{1}{6}$ field, and was sterile on culture. Urinary amino-acid chromatogram was normal. His maximum urinary concentration was 1,015 and dilution 1,002 ; maximum urea clearance was $78 \%$. Plasma ionized calcium (Dr. G. A. Rose) was $6.0 \mathrm{mg} . / 100 \mathrm{ml}$., 
complexed calcium $0.1 \mathrm{mg} . / 100 \mathrm{ml}$, and protein-bound calcium $4.0 \mathrm{mg} . / 100 \mathrm{ml}$., these results being within the normal ranges of the method at that time. His urinary calcium levels in relation to the various investigations and treatments from May 1958 to October 1959 are shown in Fig. 1. Fig. 2 shows the urinary calcium levels over a six-year period, and the results of his calcium balances are seen in Fig. 3.

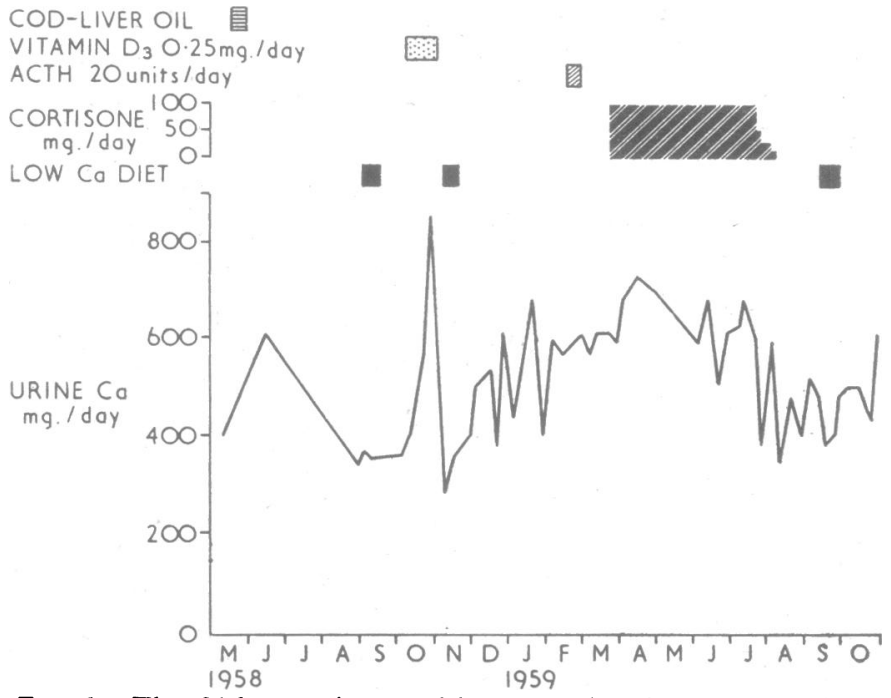

Fig. 1.-The 24-hour urinary calcium excretion from May 1958 to October 1959. The subject was on an allegedly low-calcium diet as an out-patient throughout. The periods marked "low-calcium diet" were those during calcium-balance determinations in hospital.

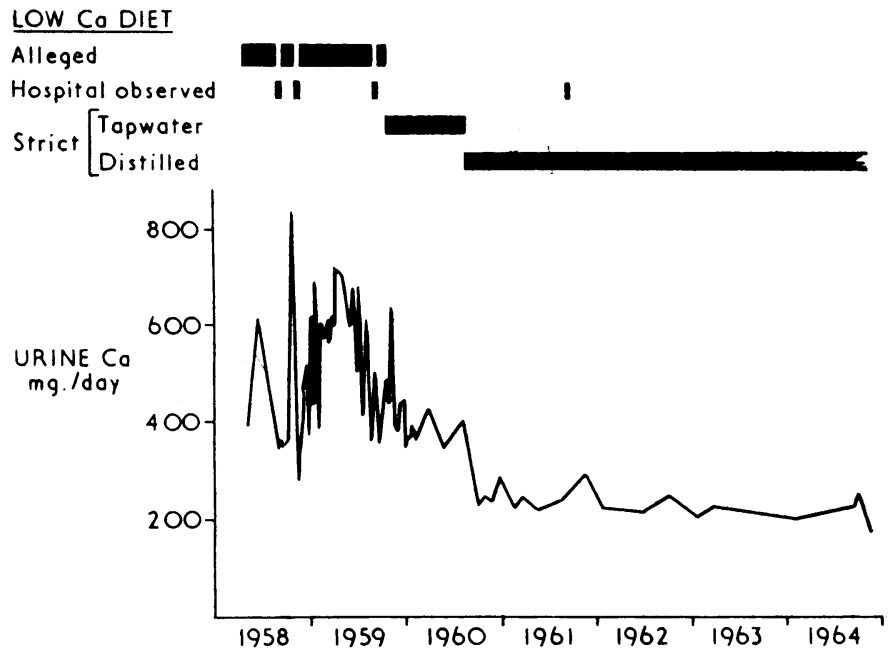

Fig. 2.-The 24-hour calcium excretion from May 1958 to the end of 1964. This graph extends and corrects Fig. 14 of Dent (1963), which was incorrect in some details relating to the year 1959.

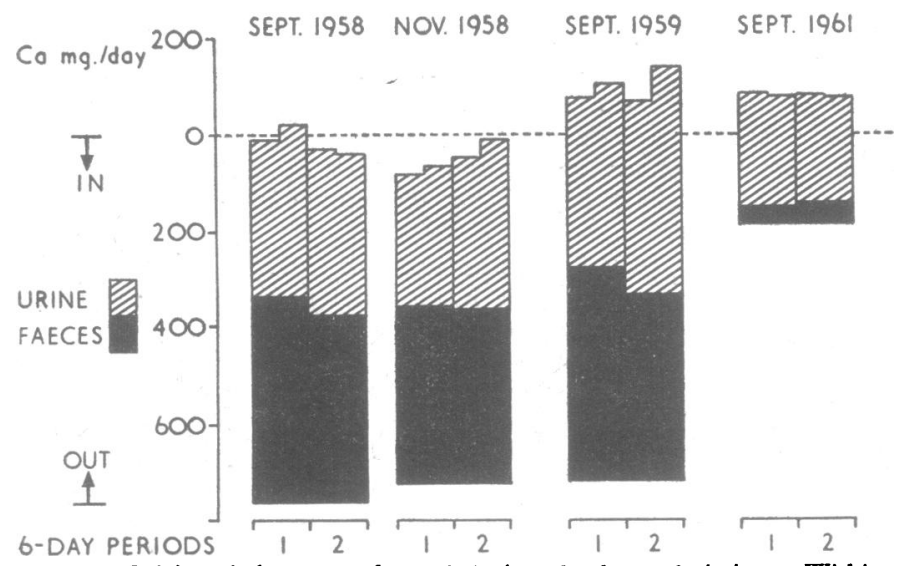

FIG. 3.-Calcium balances performed during the four admissions. Within the limits of error of the method the patient was in approximate calcium balance throughout, even on the very low intake.

\section{Calcium Balances}

He was given a diet containing $750 \mathrm{mg}$. of calcium a day, and two six-day balance periods (balance 1) were obtained. These showed that he was in approximate calcium balance but absorbing about half of the calcium ingested (Fig. 3).

$\mathrm{He}$ was discharged at the end of September and advised to continue a low-calcium diet containing about $500 \mathrm{mg}$./day. In order to investigate the possibility that vitamin-D sensitivity was the cause of his excessive gastro-intestinal absorption of calcium, he was given $0.25 \mathrm{mg}$. of vitamin $\mathrm{D}_{3}$ daily, beginning on 6 October 1958 and continuing for four weeks. Weekly determinations of his plasma and urinary calcium levels showed no significant change in the plasma but a progressive rise in urinary calcium from $350 \mathrm{mg}$./day immediately before beginning the vitamin $\mathrm{D}$ to $839 \mathrm{mg}$./day after one month's treatment. At this time he developed a severe sore throat, which was treated with penicillin and sulphadimidine. The vitamin D was stopped, and he was readmitted at once for further balance study (balance 2). His sore throat settled down during a four-day equilibration period on a similar diet to that of the first study, and he was in good health during two six-day balance periods. Surprisingly, his calcium balances were very similar to those of the first study-with a daily urinary calcium of about $300 \mathrm{mg}$. and a daily faecal calcium of about $350 \mathrm{mg}$. The likeliest explanation of his lower urinary calcium while in hospital was that it was very dependent on dietary intake and that as an out-patient he was not adhering to the lowcalcium intake advised. It did not appear that the vitamin $\mathrm{D}$ had had any effect.

It was noted too that he was drinking 4 to 5 litres of tap-water daily, whereas in hospital he was given only distilled water. His tap-water was analysed and found to contain $12 \mathrm{mg}$. of calcium/ $100 \mathrm{ml}$., so that he was receiving about $500 \mathrm{mg}$. of calcium daily from this source. Accordingly he was asked to drink only distilled water, together with his usual diet, when he returned home at the end of November 1958. The 24-hour urinary calcium was determined weekly while he was on this regime during December 1958 and January 1959 ; it showed considerable variation between 368 and $613 \mathrm{mg}$./day, and the mean daily excretion was again much higher than it had been during either of his hospital admissions.

The possible action of the adrenal corticoids in diminishing his gastro-intestinal calcium absorption and urinary calcium excretion was then investigated. He was allowed to drink tap-water again instead of distilled water and was asked to continue his approximately constant low-calcium diet of about $500 \mathrm{mg}$./day. He was given 20 units of A.C.T.H.-gel intramuscularly daily for 12 days in February 1959, and cortisone $25 \mathrm{mg}$. four times daily from 23 March to 20 July. His urinary calcium remained high (often 500-600 mg./day) with fluctuations throughout these treatments. Cortisone was then reduced and stopped completely after three weeks.

Apart from one severe respiratory infection and occasional attacks of renal colic he remained well throughout this time, and in September 1959 he was readmitted for a further balance study (balance 3). On the same diet containing about $700 \mathrm{mg}$. of calcium daily his balance picture was essentially the same as in balances 1 and 2 . On this occasion he was in slightly negative calcium balance with a urinary and a faecal calcium each about $400 \mathrm{mg}$. daily (Fig. 3).

\section{Further Investigations and Treatment}

A careful assessment was made at this stage. It was clear that he was absorbing calcium excessively from the diet, and this did not appear to be due to vitamin-D sensitivity, since the administration of vitamin D (see balance 2) did not appear to increase his gastrointestinal absorption and the administration of cortisone did not lower his urinary calcium (Fig. 1). As no aetiological factor, such as vitamin-D sensitivity or occult sarcoidosis, had been discovered it was becoming clearer that we had to describe him as suffering from idiopathic hypercalciuria. Furthermore, it was likely that his urinary calcium was very dependent on dietary intake, since it had been lowest during the time he was under investigation in hospital on a strict calcium intake of about $700 \mathrm{mg}$. daily and drinking distilled water.

In November 1959 he was put on a very low calcium diet containing about $200 \mathrm{mg}$. of calcium a day. His urinary calcium then ceased to fluctuate as much as before but remained high at about $400 \mathrm{mg}$./day (Fig. 2). He was, of course, drinking large 
amounts of tap-water as before. In September 1960 he was asked to drink only distilled water in addition to the very strict low-calcium diet. Immediately his urinary calcium fell further and remained between 200 and $250 \mathrm{mg}$./day throughout the next four years (Fig. 2).

In September 1961 he looked and felt very well and had had no further attacks of renal colic since beginning the very strict lowcaloium diet in November 1959. It appeared, too, on reviewing his $x$-ray films, that, although there had been a slight increase in the size of the renal stones between the first examination of June 1958 and October 1959, there had been no further change while on the strict low-calcium diet between November 1959 and September 1961. His urine was still free of infection. The chief concern now was that he might have gone into a serious degree of negative calcium balance with a long-term risk of damaging his bones.

To investigate this possibility he was readmitted in September 1961 for further calcium-balance studies (balance 4). After a five-day equilibration period on a diet containing $184 \mathrm{mg}$. of calcium daily, two six-day periods were obtained (Fig. 3). These showed that the faecal calcium was very low indeed (about $50 \mathrm{mg}$. daily) and that he was in negative calcium balance of about $80 \mathrm{mg} . /$ day in each period, with a urinary calcium of about $220 \mathrm{mg}$. daily. It was considered that this result was satisfactory, and he was discharged to continue on the same regime.

He remained well. Further $x$-ray examinations in November 1962 and January 1963 showed that the stones in the left kidney had not increased in size, although one of them had shifted its position. There were still no stones in the right kidney. His urinary calcium remained between 200 and $250 \mathrm{mg}$. daily. Between April 1963 and February 1964 he returned to Australia and while there developed an attack of left-sided renal pain, this being the first he had had for almost four years.

He was reassessed when he returned to England in February 1964. His general health was good. His height was unaltered at $176 \mathrm{~cm}$. (5 ft. 9 in.), his blood-pressure was 130/95, and he had developed no new physical signs. His urinary calcium was $199 \mathrm{mg}$./ day, and urinary examination was unchanged since 1958, showing a slight trace of protein, and 6-8 white cells and $2-4$ red cells per $\frac{1}{6}$ field. Urinary culture was sterile. $X$-ray films did not show any loss of bone density, and intravenous pyelography performed in June 1964 showed that the right kidney measured $13 \mathrm{~cm}$. and the left $13.5 \mathrm{~cm}$. Both had smooth outlines and had not altered in size or shape since 1958. Both kidneys excreted the contrast medium promptly and equally and no stones were seen in the right kidney or either ureter. The stones in the left kidney had again increased somewhat in size since the examination of January 1963 before he returned to Australia. There were dilated calices as before in both the upper and lower groups on the left side.

On 3 October 1964 he suddenly developed an aching pain in the left lumbar region. This increased in severity during the next two days and developed a stabbing quality so that he needed pethidine to relieve the pain. $X$-ray examination showed no recent change in the size or position of the stones and urinary examination was also unchanged, urinary culture being sterile. After the pain had been present continually for about one week, with occasional severe exacerbations for which pethidine was needed, it was decided to remove the stones, and this was done on 12 October 1964 by $\mathrm{Mr}$. D. R. Davies, who also performed left lower partial nephrectomy. The calices of the left upper pole were found to be dilated and the kidney substance rather thin, confirming the findings of intravenous pyelography.

$\mathrm{He}$ made an uneventful recovery from the operation, drinking large quantities of distilled water and passing five to six litres of urine daily from the first post-operative day. His plasma urea remained normal throughout. His urinary calcium was $266 \mathrm{mg}$. and urinary oxalate $57 \mathrm{mg}$. (Dr. P. M. Zarembski) on the ninth day after operation, when the urinary culture was still sterile. Three months later he looked and felt well and his 24-hour urinary calcium was $174 \mathrm{mg}$. He was, of course, still adhering to his very low calcium diet with copious distilled water to drink.

\section{Discussion}

It is quite clear that this patient is suffering from idiopathic hypercalciuria. His fasting plasma calcium was normal (9.6-10.1 mg./100 ml.) throughout the study and there were no clinical or radiological features of other causes of hypercalciuria (such as bone disease, excessive ingestion of vitamin $\mathrm{D}$, or sarcoidosis). Initially we were impressed by the history that an exacerbation of his symptoms may have been produced by the ingestion of small amounts of vitamin $D$, with a consequent rise in urinary calcium, and the initial investigations seemed to support this possibility, since his urinary calcium increased considerably when he was given a small dose of vitamin $\mathrm{D}$ as an out-patient. However, this rise in urinary calcium soon appeared more likely to be due to a further increase in dietary calcium intake than to a vitamin-D-induced increase in gastro-intestinal absorption. This was confirmed when the second balance periods on the original calcium intake obtained immediately after he had taken vitamin D showed the same picture as before taking the vitamin. When, in addition, the administration of A.C.T.H. and cortisone failed to lower his urinary calcium we thought that vitamin-D sensitivity had been finally excluded as the cause of his disease.

It may be pointed out that his 24-hour urinary oxalate excretion was $57 \mathrm{mg}$., a figure beyond the usually accepted normal range of $10-28 \mathrm{mg}$./24 hours, but still well below the figures obtained in essential hyperoxaluria (Zarembski and Hodgkinson, 1965). We are currently investigating the possibility that such a lesser degree of increased urinary oxalate excretion may be of pathological significance when combined with another defect such as hypercalciuria. Such a hypothesis, even if confirmed, does not affect the main points we are making here.

We think that these studies cast some light on the mechanism of the hypercalciuria in this case. In each of the four balance studies there was evidence of well-marked overabsorption of dietary calcium. This is seen in the first three studies, which all show an absorption of about $50 \%$ of the ingested calcium on an intake of about $800 \mathrm{mg}$. daily, but it is even more striking in the study performed about two years after he began his very low calcium diet, when he was absorbing about threequarters of an intake of less than $200 \mathrm{mg}$./day. Furthermore, he remained in approximate calcium balance throughout and his urinary calcium showed a very great degree of dependence on dietary intake. These observations provide good evidence that the primary defect of calcium metabolism in this patient could be an inability of the gastro-intestinal mucosa to limit the absorption of calcium in the usual way, resulting in excessive gastro-intestinal absorption. These results are different from the shorter-term studies on two similar patients reported by Jackson and Dancaster (1959). They emphasized that the urine calcium was not so dependent as we have found on dietary intake. Hence they preferred to consider a renal calcium leak with secondary overabsorption from the gut to be a more likely mechanism. We have other work in progress which suggests that the behaviour of our patient is much more representative of this group of patients.

Some points of interest arise in comparing the results of this patient's studies with those we have recently reported from a child with osteopetrosis (Dent et al., 1965). This latter patient also showed a very marked overabsorption of calcium from the gut, even greater in degree than the present patient, for his faecal calcium was negligible on a low-calcium intake of about $100 \mathrm{mg}$./day. Unlike the present patient, however, he remained in quite strongly positive calcium balance even on this very low intake and did not go into negative calcium balance under any of the experimental conditions that we tried. We postulated that while the gastro-intestinal overabsorption of calcium was a striking and important manifestation of osteopetrosis, it had not been proved to be the primary defect. It seemed likely that the bones themselves had an increased ability to take up calcium from the circulating body fluids, this being a further basic biochemical abnormality and perhaps the primary defect in osteopetrosis. The present patient does not manifest this bony defect, and it appears that he has a primary lesion only in the gastro-intestinal mucosa leading to excessive 
absorption of calcium, which is then disposed of by his kidneys, while patients with osteopetrosis have an additional defect which causes them to store the extra calcium in their bones. Hypercalciuria and renal stone formation are certainly not features of osteopetrosis.

The very great degree of the gastro-intestinal overabsorption in this patient is also of importance because of the practical problems which it presented. A low-calcium diet alone did not lower his urinary calcium sufficiently, and it was not until we asked him to drink only distilled water in addition to his very strict low-calcium diet that adequate control was achieved. Obviously a large urinary volume is just as important as a low urinary calcium in producing a low urinary calcium concentration, and we always advise our stone-forming patients to drink a lot of fluid in order to maintain a high urinary volume. Since London tap-water is so hard, they need to drink softened water, distilled water as used by this patient being the most satisfactory. Another practical difficulty of the regime is that it is rather expensive to maintain an interesting and varied diet of very low calcium content, but, despite this, it is fully practical, as evidenced by this patient's enthusiastic adherence to the full regime for over four years.

We have no doubt that the regime has lessened the rate of renal stone formation and the incidence of renal colic in this patient. Reviewing his $x$-ray pictures carefully, it is clear that there was an increase in the size of the stones in the left kidney between June 1958 and October 1959 while we were performing investigations of the nature and aetiology of the hypercalciuria, and he usually had a high urinary calcium. For the next three and a half years after beginning the strict low-calcium regime the stones did not increase in size, although one of them shifted its position. In 1963 he returned to Australia and was not under careful supervision for about a year. His stones had increased somewhat in size when we saw him again in England in 1964. During this year he also developed renal colic for the first time since 1959, and this culminated in a severe attack necessitating removal of the stones later in 1964. We were not too surprised at this, since the difficulties of travelling long distances with inevitable domestic upheaval must have made it almost impossible for him to adhere to the full regime at all times. He did not form any new stones in the stone-free right kidney and has not formed stones in the left kidney during the short period of observation since operation.

The chief danger of the treatment is the possibility that he will damage his bones as a result of the prolonged negative calcium balance, but all the evidence on this point is so far reassuring. He continues to feel well without any complaints referable to his bones, his height has remained unaltered in the six years since 1958 , and his most recent $x$-ray films show the bones to be of normal density without any radiological features suggestive of osteoporosis. In addition we consider that the calcium balances performed about two years after beginning the very strict low-calcium regime are satisfactory from this point of view. As this patient illustrates an extreme example of what we suspect to be a very common defect we have a possible explanation of the difficulty in deciding on what are the optimal dietary calcium requirements in the human (F.A.O./W.H.O., 1962). Clearly this patient's life would be endangered by a daily intake of only $1 \mathrm{~g}$. of calcium, a quantity taken by most normal people. The reverse situation is also suspected to occur in some cases of osteoporosis when there is an inherent inability to absorb dietary calcium. Just how far this can be overcome by increasing the calcium intake in such patients is, however, still not clear. The problem of assessing dietary calcium requirements in the face of various known and commonly occurring abnormalities of calcium metabolism has been briefly reviewed by one of us (Dent, 1963).

\section{Summary}

The case is described of a patient with idiopathic hypercalciuria and renal stone formation.

Calcium-balance studies performed on four separate occasions always showed excessive absorption of calcium from the diet.

The hypercalciuria lessened when the patient was put on a strict low-calcium diet, but it was not fully controlled until he was also instructed to use only distilled water for drinking and for use in cooking.

He has remained well for over five years on a diet containing about $200 \mathrm{mg}$. of calcium daily. Calcium-balance studies carried out about two years after the regime was instituted showed that he was in approximate calcium balance. $X$-ray films to date show no evidence of osteoporosis. Our data strongly suggest that the primary defect in this case is gut overabsorption and that his dietary requirement of calcium is therefore very low.

We wish to thank the biochemical, dietetic, and nursing staffs of the Metabolic Ward, University College Hospital, for their valuable assistance in performing these studies. One of us (L.W.) is in receipt of a generous grant from the British Empire Cancer Campaign.

\section{REFERENCES}

Albright, F., Henneman, P., Benedict, P. H., and Forbes, A. P. (1953). 7. clin. Endocr., 13, 860 .

Dent, C. E. (1963). Wiss. Veröff dtsch. Ges. Ernährung, 13, 10. Harper, C. M., and Parfitt, A. M. (1964). Clin. Sci., 27, 417.

- Smellie, J. M., and Watson, L. (1965). Arch. Dis. Childh., 40, 7. F.A.O./W.H.O. Calcium Requirements (1962). F.A.O. Nutrition Meetings Report Series, No. 30. U.N. Rome.

Fleisch, H. (1962). Schweiz. med. Wschr., 92, 1197.

- and Bisaz, S. (1962a). Amer. F. Physiol., 203, 671.

- 1 and b). Nature (Lond.), 195, 911 .

Flocks, R. H. (1939). F. Amer. med. Ass., 113, 1466.

Henneman, P. H., Benedict, P. H., Forbes, A. P., and Dudley, H R. (1958). New Engl. ₹. Med., 259, 802 .

Hodgkinson, A. (1961). Proc. Ass. clin. Biochem., 1, 52.

and Pyrah, L. N. (1958). Brit. F. Surg., 46, 10.

Jackson, W. P. U., and Dancaster, C. (1959). F. clin. Endocr., 19, 658

Parfitt, A. M., Higgins, B. A., Nassim, J. R., Collins, J. A., and Hilb, A. (1964). Clin. Sci., 27, 463.

Zarembski, P. M., and Hodgkinson, A. (1965). Biochem. f. In press. 